\title{
Relations between Climatic Changes and High Pollution Levels in Bulgaria
}

\author{
Zahari Zlatev1, Ivan Dimov², Krassimir Georgiev² \\ ${ }^{1}$ Department of Environmental Science, Aarhus University, Roskilde, Denmark \\ ${ }^{2}$ Institute of Information and Communication Technologies, Bulgarian Academy of Sciences, Sofia, \\ Bulgaria \\ Email: zz@envs.au.dk, ivdimov@bas.bg, georgiev@parallel.bas.bg
}

Received 10 June 2016; accepted 11 July 2016; published 14 July 2016

Copyright (C) 2016 by authors and Scientific Research Publishing Inc.

This work is licensed under the Creative Commons Attribution-NonCommercial International License (CC

BY-NC).

http://creativecommons.org/licenses/by-nc/4.0/

(c) () () (9) Open Access

\section{Abstract}

One of the important consequences of the climatic changes is the potential danger of increasing the concentrations of some pollutants, which may cause damages to humans, animals and plants. Therefore, it is worthwhile to study carefully the impact of future climate changes on the high pollution levels. The major topic of the discussion in this paper is the increase of some ozone levels in Bulgaria, but several related topics are also discussed. The particular mathematical tool applied in this study is a large-scale air pollution model, the Unified Danish Eulerian Model (UNIDEM), which was successfully used in several investigations related to potentially dangerous pollution levels in several European countries. This model is described by a non-linear system of partial differential equations, which is solved numerically by using (a) advanced numerical algorithms and (b) modern computer architectures. Moreover, (c) the code is parallelized and (d) the cache memories of the available computers are efficiently utilized. It is shown that in Bulgaria, as in the other European countries, the climatic changes will result in permanent increases of some quantities related to the ozone pollution. The important issue is that in our study the changes of the dangerous pollution levels are followed year by year. In this way, an attempt is made both to capture the effect of the inter-annual variations of the meteorological conditions on the levels of the ozone concentrations and to follow directly the influence of the climatic changes on the pollution levels. Moreover, the sensitivity of the pollution levels to variations of the human made (anthropogenic) and natural (biogenic) emissions is also discussed.

\section{Keywords}

Air Pollution Models, Partial Differential Equations, Climatic Scenarios, Ozone Concentrations 


\section{Statement of the Problem}

Changes in climate variability and extreme weather and climate events in the end of 20th century and in the beginning of the 21st century have been discussed in many recent scientific publications. Attempts to project the results of such studies in the future have been made under different assumptions. In this study: (i) well-known scenarios predicting changes of the climate in the last 30 years of the 21st century for the territory of Bulgaria and the surrounding area will be taken into account and (ii) impact of these changes on the future pollution levels will be studied and discussed. There are many uncertainties related to the climate changes in the future (Houghton et al., 2001). It is nevertheless worthwhile to investigate the impact of possible climatic changes on the pollution levels.

The increase of the global temperature of the Earth would certainly cause some changes of the concentrations of many of the damaging chemical species. There are two major reasons, which lead to an increase of the pollution levels: (1) many of the chemical reactions depend on the temperature and (2) the relative parts of the biogenic emissions are becoming bigger when the temperature is higher. This is why the global warming will lead in the most of the cases to an increase of the dangerous effects of the high concentrations of pollutants in the atmosphere on humans, animals and plants. Therefore, the relationship between the global increase of the temperature and the pollution levels should be carefully studied. In this paper, the area of interest is Bulgaria and the major topics discussed in it are

(a) the influence of the climate changes (and, first and foremost, of the increased temperature) on the pollution levels in the selected area,

(b) the changes of the pollution levels that are due to a combination of the warming effect with some other important factors and

(c) the contribution of air pollution transported from other European countries to the ozone levels in Bulgaria.

The study was carried out by using 14 elaborated scenarios. Most of the selected scenarios were also discussed in [1]-[6]. These scenarios were run over a long time period with a well-known air pollution model, the Unified Danish Eulerian Model (UNI-DEM), fully described in [7]-[13]. It should be mentioned here that this air pollution model was used in several other advanced air pollution studies related to

1) the Balkan Peninsula [4],

2) Bulgaria [14] [15],

3) Denmark [6] [10] [16] [17],

4) England [18],

5) Europe [1]-[3] [8] [9] [12] [13] [16],

6) Hungary [5] [19] [20] and

7) the North Sea [21].

A previous version of UNI-DEM was additionally used in some inter-comparisons of several well-known European large-scale air pollution models [22] [23].

The contents of the present paper can be summarized as follows:

- UNI-DEM is sketched in Section 2,

- the need to take into account the sensitivity of the model results to variations of the important inter-annual variations of the meteorological conditions is justified in Section 3,

- some issues related to the human-made (anthropogenic) and natural (biogenic) emissions are briefly discussed in Section 4,

- a short description of the climatic scenarios is given in Section 5,

- some results demonstrating the increase of the pollution levels in Bulgaria are presented in Section 6,

- $\quad$ several conclusions are given in Section 7.

\section{Mathematical Description of UNI-DEM}

UNI-DEM is described by a non-linear system of partial differential equations (PDEs). Five important physical and chemical processes are taken into account during the derivation of the system of PDEs. These processes are listed below:
(a) horizontal transport (advection),
(b) horizontal diffusion,
(c) non-linear chemical reactions plus emission sources,
(d) dry and wet deposition and 
(e) vertical exchange.

The non-linear system of PDEs is written in the following form:

$$
\begin{aligned}
& \text { (1) } \frac{\partial c_{i}}{\partial t}=-u \frac{\partial c_{i}}{\partial x}-v \frac{\partial c_{i}}{\partial y} \quad \text { horizontal transport (advection) } \\
& +\frac{\partial}{\partial x}\left(K_{x} \frac{\partial c_{i}}{\partial x}\right)+\frac{\partial}{\partial y}\left(K_{y} \frac{\partial c_{i}}{\partial y}\right) \quad \text { horizontal diffusion } \\
& +Q_{i}\left(t, x, y, z, c_{1}, c_{2}, \cdots, c_{q}\right)+E_{i}(t, x, y, z) \quad \text { chemical reactions + emissions } \\
& +\left(k_{1 i}+k_{2 i}\right) c_{i} \quad \text { dry and wet depositions } \\
& -w \frac{\partial c_{i}}{\partial z}+\frac{\partial}{\partial z}\left(K_{z} \frac{\partial c_{i}}{\partial z}\right), \quad \text { vertical transport } \\
& i=1,2, \cdots, q
\end{aligned}
$$

The concentrations of the chemical species at point $(x, y, z)$ of the space domain and at time $t$ are denoted by $c_{i}=c_{i}(t, x, y, z)$. The notation $u=u(t, x, y, z), v=v(t, x, y, z)$ and $w=w(t, x, y, z)$ is used for the wind velocities along the $O x, O y$ and $O z$ directions. The diffusivity coefficients are $K_{x}=K_{x}(t, x, y, z)$, $K_{y}=K_{y}(t, x, y, z)$ and $K_{z}=K_{z}(t, x, y, z)$, while $k_{1 i}=k_{1 i}(t, x, y, z)$ and $k_{2 i}=k_{2 i}(t, x, y, z)$ are deposition coefficients. The non-linear terms in the third line of Equation (1) define the chemical reactions. Finally, the terms $E_{i}(t, x, y, z)$ are describing emission sources, including both human-made (anthropogenic) emissions and natural (biogenic) emissions.

The discretization of the system of PDEs by which the environmental models are described mathematically leads to huge computational tasks. The following example illustrates clearly the size of these tasks. Assume that

- $\quad N_{x}=N_{y}=480$ (a $4800 \mathrm{~km} \times 4800 \mathrm{~km}$ domain covering Europe is considered and this choice of the discretization parameters; it leads to the application $10 \mathrm{~km} \times 10 \mathrm{~km}$ horizontal cells),

- $\quad N_{z}=10$ (i.e. ten layers in the vertical direction, which are not equidistant, are introduced) and

- $N_{\mathrm{s}}=q=56$ (this means that the chemical scheme contains 56 species).

Then the number of equations that are to be handled at each time-step is equal to $\left(N_{x}+1\right)\left(N_{y}+1\right)\left(N_{z}+1\right) N_{s}=142518376$. A run over a time-period of one year with a time stepsize $\Delta t=2.5$ seconds will result in $N_{t}=213120$ time-steps. If studies related to climatic changes are to be carried out, then it is necessary to run the model over a time-period of many years (sixteen consecutive years were actually used in this study). Additionally, the sensitivity of the model to the variation of some parameters is to be studied by using many scenarios (this implies that many hundreds of time and storage consuming runs had to be carried out). This short analysis demonstrates the fact that the computational tasks arising when climatic studies are to be performed by using large-scale models are enormous. Therefore, the following three conditions must be satisfied; it is necessary

- to select fast but sufficiently accurate numerical methods,

- to exploit efficiently the cashes of the available computer,

- to parallelize carefully the code

in the efforts to make a large environmental model tractable on the available computer architectures. It should be mentioned that it may be impossible to handle some very large environmental models on the computers available at present even when the above three conditions are satisfied. Therefore, it is also necessary to use appropriate splitting procedures.

UNI-DEM is split (as described in [7] and [13]) into the following three sub-models and an attempt to select optimal numerical algorithms for every sub-model is carried out.

$$
\begin{aligned}
& \text { (2) } \frac{\partial c_{i}^{(1)}}{\partial t}=-w \frac{\partial c_{i}^{(1)}}{\partial z}+\frac{\partial}{\partial z}\left(K_{z} \frac{\partial c_{i}^{(1)}}{\partial z}\right) \\
& \text { (3) } \frac{\partial c_{i}^{(2)}}{\partial t}=-u \frac{\partial c_{i}^{(2)}}{\partial x}-v \frac{\partial c_{i}^{(2)}}{\partial y}+\frac{\partial}{\partial x}\left(K_{x} \frac{\partial c_{i}^{(2)}}{\partial x}\right)+\frac{\partial}{\partial y}\left(K_{y} \frac{\partial c_{i}^{(2)}}{\partial y}\right), \\
& \text { (4) } \frac{\partial c_{i}^{(3)}}{\partial t}=Q_{i}\left(t, x, y, z, c_{1}^{(3)}, c_{2}^{(3)}, \cdots, c_{q}^{(3)}\right)+E_{i}(t, x, y, z)+\left(k_{1 i}+k_{2 i}\right) c_{i}^{(3)} .
\end{aligned}
$$


The first of these three sub-models describes the vertical exchange. The second sub-model describes the combination of the horizontal transport (the advection) and the horizontal diffusion. The last sub-model describes the chemical reactions together with the emission sources in the studied domain and the deposition terms.

The use of this splitting procedure allows us

(a) to select optimal numerical methods for every sub-model,

(b) to facilitate the parallelization of the code and

(c) to utilize in a better way the cache memories of the available computer.

It should be emphasized here that the particular splitting procedure applied in connection with UNI-DEM does not require extra and artificial boundary conditions. Much more details about the computer treatment of UNI-DEM can be found [10] and [13].

\section{Importance of the Inter-Annual Variations of the Meteorological Conditions}

Fourteen scenarios were developed and successfully used in [1]-[5]. Each scenario was run over a time-period consisting of sixteen consecutive years (from 1989 to 2004). In this paper mainly results obtained by using the Basic Scenario and the Climatic Scenarios 1, 2 and 3 will be reported. It should additionally be mentioned that ideas, different devices and data from [24]-[38] were used both in the preparation of the climatic scenarios in the particular runs. It must be emphasized here that the scenarios were designed so that the inter-annual variations of the concentrations were taken into account. This is important, because some of the critical levels legislated by the European Parliament, see details in [31], are to be calculated in relatively short summer periods and cold or warm weather during these periods will lead to big differences. The great annual inter-variations of the averaged daily ozone maxima around the Bulgarian capital Sofia are demonstrated in Figure 1.

It should be pointed out that rather large variations of annual averages of concentrations were observed also in other parts of Europe and for other pollutants too (see [1]-[6] [8] and [25]). The variations of the ammonium + ammonia levels in the Danish area are shown in Figure 2. Results obtained with five different scenarios are shown in this figure. The Basic Scenario was run with the actual emissions and meteorological conditions. The 2010 Scenario was run with levels of the anthropogenic emissions, which were planed in the end of the twentieth century for year 2010. The MFR (Maximum Feasible Reduction) Scenario assumes that the anthropogenic

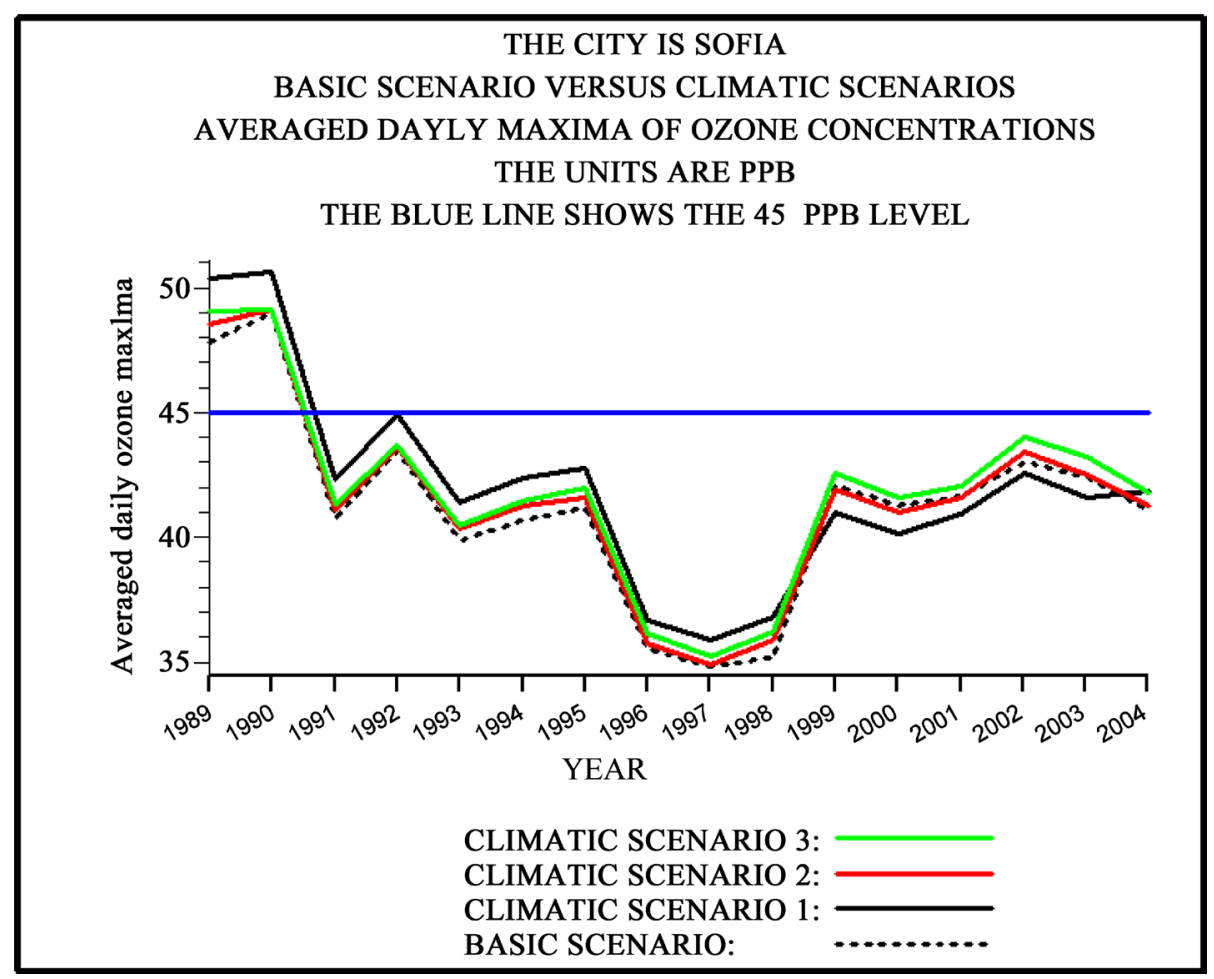

Figure 1. Variations of the averaged daily maxima of the ozone concentrations during a period of 16 years. 


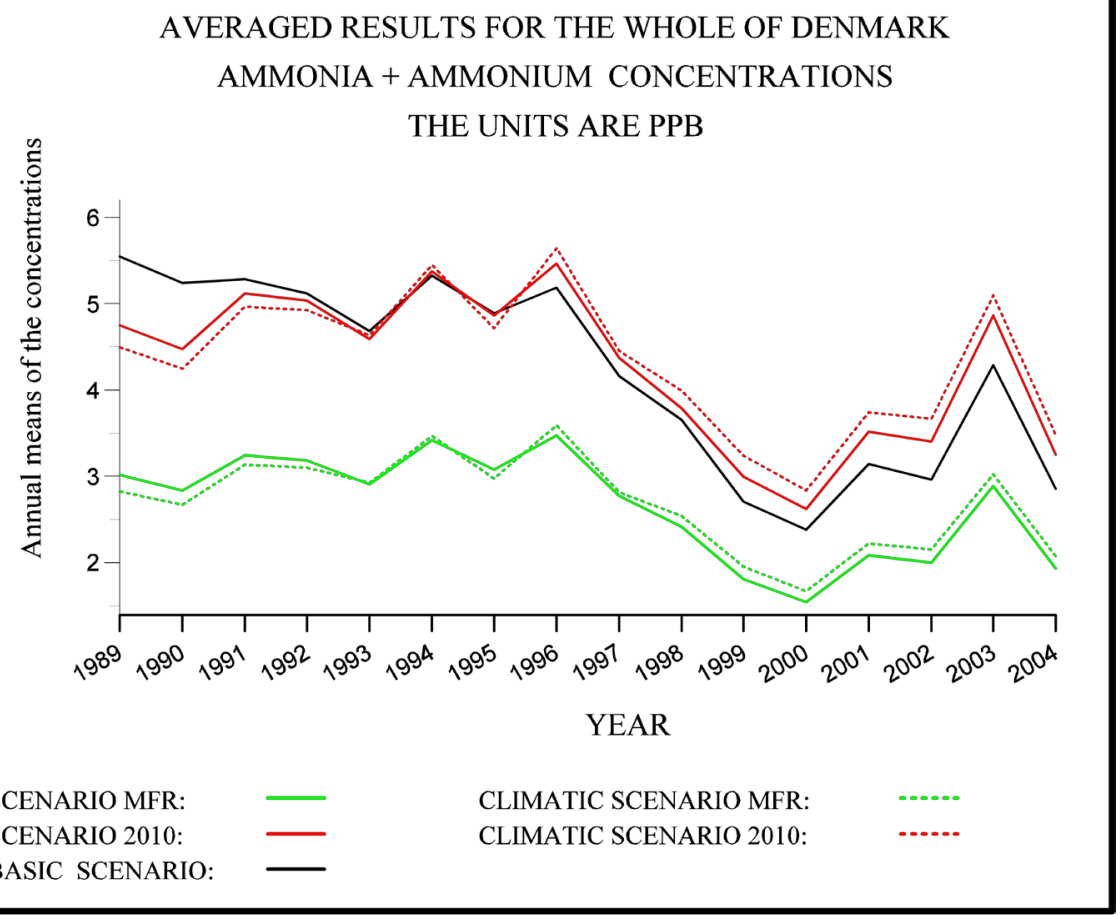

Figure 2. Variations of the yearly averages of the ammonia-ammonium concentrations in Denmark.

emissions will be reduced very significantly (up to $90 \%$ in some countries). Both scenarios were developed at IIASA (the International Institute for Applied System Analysis in Laxenburg, Austria; see more details in [24].The two climatic scenarios are based on the use of the recommendations proposed in IPCC SRES A2 Scenario in Scenario 2010 and the MFR Scenario. The following conclusions can be drawn from the results presented in Figure 2 as well as from results presented in some previous studies [1]-[6] [8] and [25]:

(a) the inter-annual variations remain for all five scenarios (see again [1]-[6] [8] and [25]),

(b) the differences between the results obtained by the Basic Scenario and those found when Scenario 2010 and

Climate Scenario 2010 are used are rather small for this pollutant, while the MFR Scenario leads to a large decrease of the pollution levels and

(c) the influence of the climate changes is not very significant when annual values of ammonia + ammonium concentrations are studied.

\section{Scenarios with Human-Made and Natural Emissions}

The fact that the European human-made (anthropogenic) emissions (including here the Bulgarian emissions) were reduced during the studied period was taken into account in this investigation. The reduction of the Bulgarian emissions is shown in Figure 3. It is seen that the reduction of the emissions in this country is rather significant (up to $60 \%$ for some of the emissions). It must be emphasized that the reduction of the Bulgarian emissions during this period was not an isolated case. The reduction of the emissions in Europe as a whole is shown in Figure 4. It is immediately seen that the trend is the same. More examples, which show that the emissions in the European countries were reduced are given in [1].

The decrease of the human-made (anthropogenic) emissions leads to an increase of the relative part and, thus, of the importance of the natural (biogenic) emissions. The biogenic emissions in the Unified Danish Eulerian Model are created by using ideas described in [34] [37] and [38]. Similar ideas are also used in some other air pollution models. However, it should be mentioned here that some scientists claim that the natural emissions are greatly underestimated (see, for example, [25] [27] and [28]). Therefore, it was also useful to develop and apply some scenarios in which the natural (biogenic) emissions are varied.

It should furthermore be emphasized that both the emission sources and the meteorological data are very 


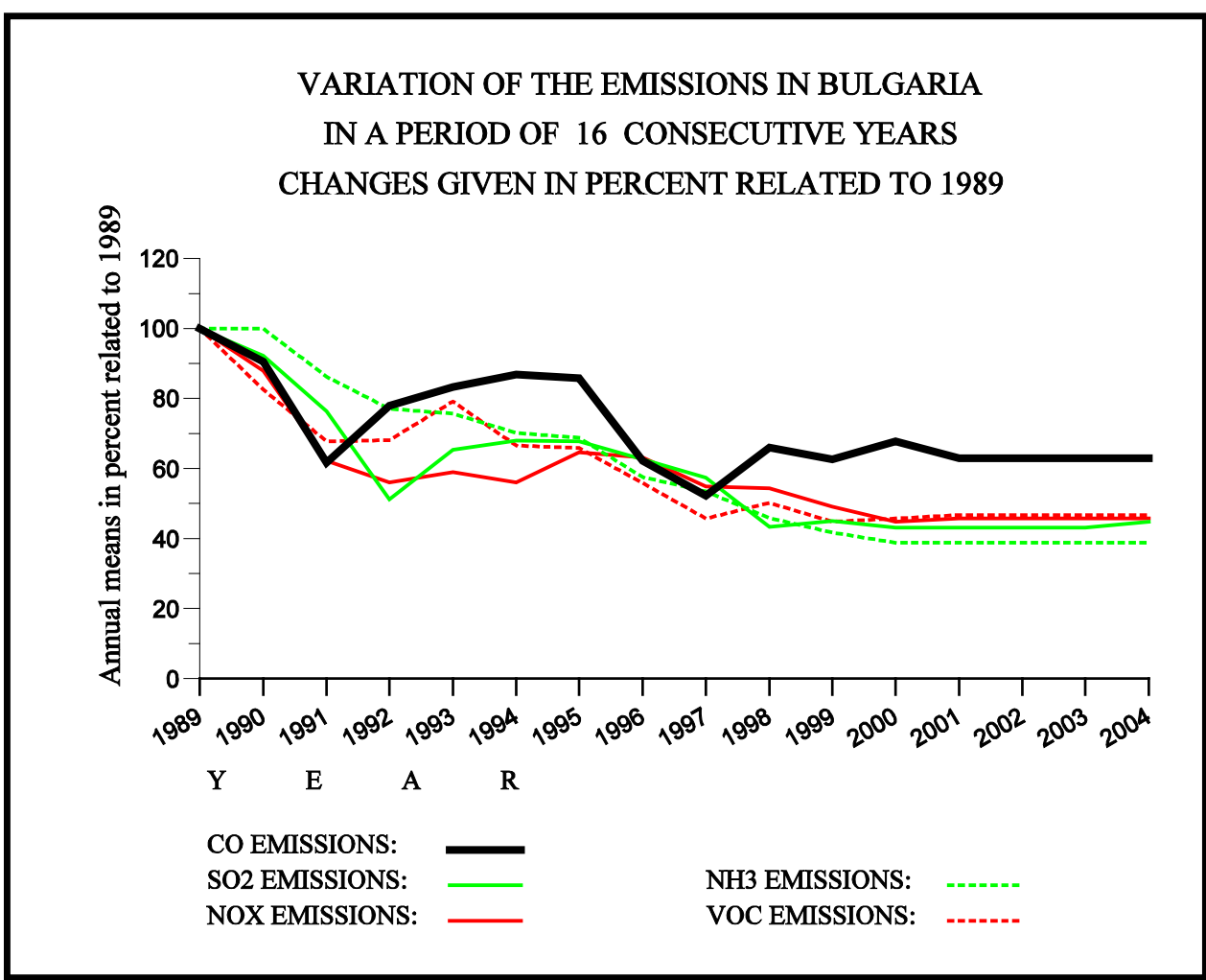

Figure 3. Changes of the Bulgarian human-made emissions during the period from 1989 to 2004.

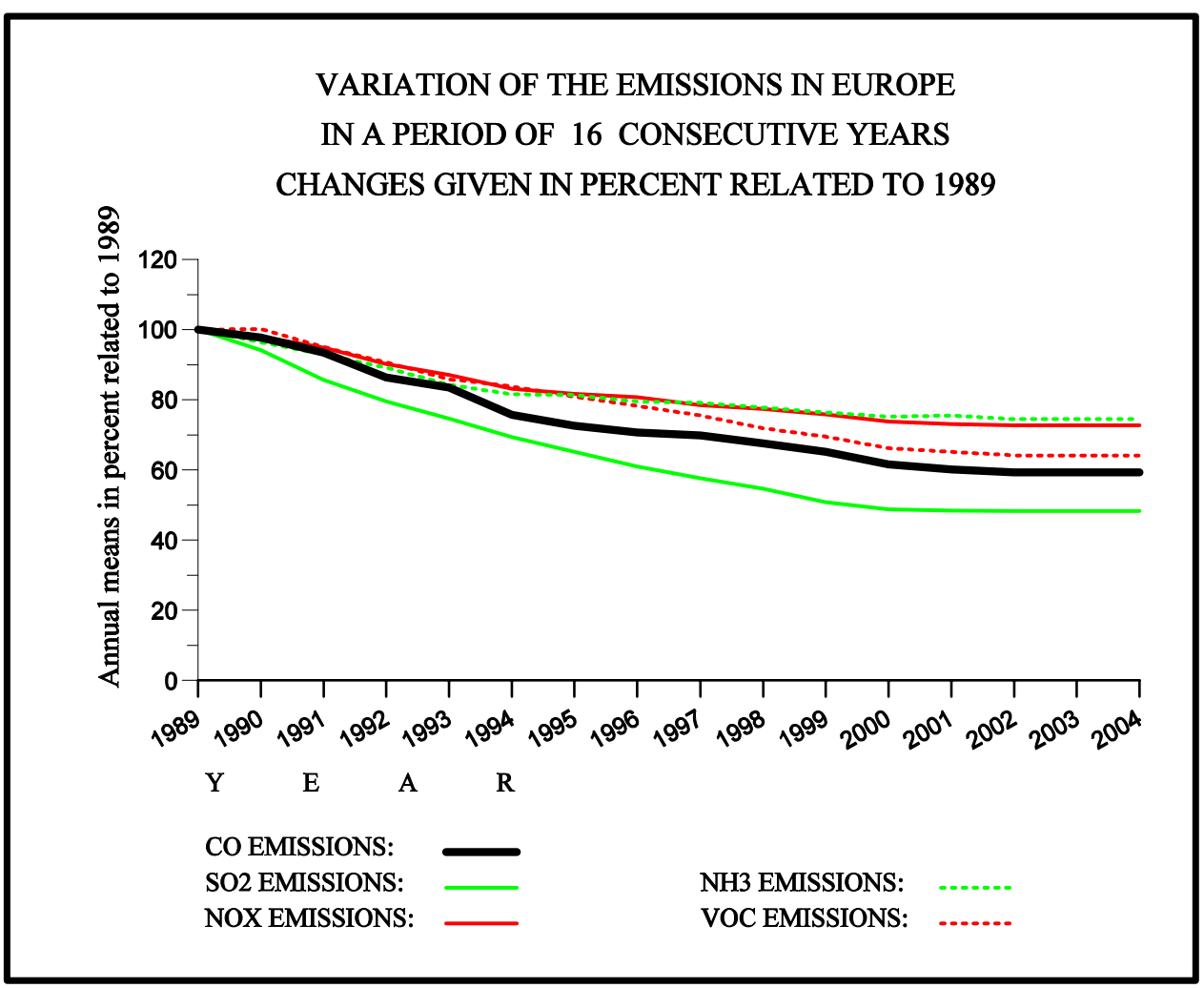

Figure 4. Changes of the European human-made emissions during the period from 1989 to 2004. 
important. This is illustrated by the results presented in Figure 5, which were obtained by running three emission scenarios. It is seen that if the emissions sources are kept constant, then one can see the annual variations but not the trend of decreasing of the concentrations (caused by the decreased emissions). If the meteorological conditions are kept constant, then it is not possible to see the annual variations, but the decreasing trend is preserved. Therefore, all scenarios were run with the actual emissions and with the actual wind fields (which is also true for the climatic scenarios). This allows us both to compare the differences between the results obtained by different scenarios for every chosen year from the selected time-interval of 16 years and to demonstrate the fact that there are considerably large inter-annual variations of the pollution levels.

\section{Scenarios with Human-Made and Natural Emissions}

Some of the results that are related to the increase in the annual temperatures in Europe according to the IPCC SRES A2 Scenario as well as several other conclusions, which are related to the climatic changes in Europe and which are discussed in [35], were used in order to prepare three climatic scenarios. The basic rules, which were actually used in the development of these scenarios, are sketched below.

Climate Scenario 1: The predicted annual changes of the temperature (see [35]), were used to produce this climatic scenario. The changes of the temperature in Europe resulting from this scenario are shown in Figure 6. Consider any cell of the grid used to create the plot shown in Figure 6 and assume that this cell is located in a region in Figure 6 where the increase of the temperature is in the interval $[a, b]$. The temperature in the chosen cell at hour $n$ ( $n$ being any hour in the interval from 1989 to 2004) is increased by an amount $a+c(n)$, where $c(n)$ is randomly generated and uniformly distributed in the interval $[0, b-a]$ so that the mathematical expectation of the increase of the annual mean of the temperature at any cell of the space domain is $(b-a) / 2$. This means that (a) only temperatures are varied in this scenario and (b) the mean value of the annual change of the temperature at a given point will tend to be the same as that prescribed by the IPCC SRES A2 Scenario.

Climate Scenario 2: The extreme cases will become even stronger in the future climate; see Table 9.6 on p. 575 in [23]. It is expected that:

(a) there will be higher maximum temperatures and more hot days over the land areas,

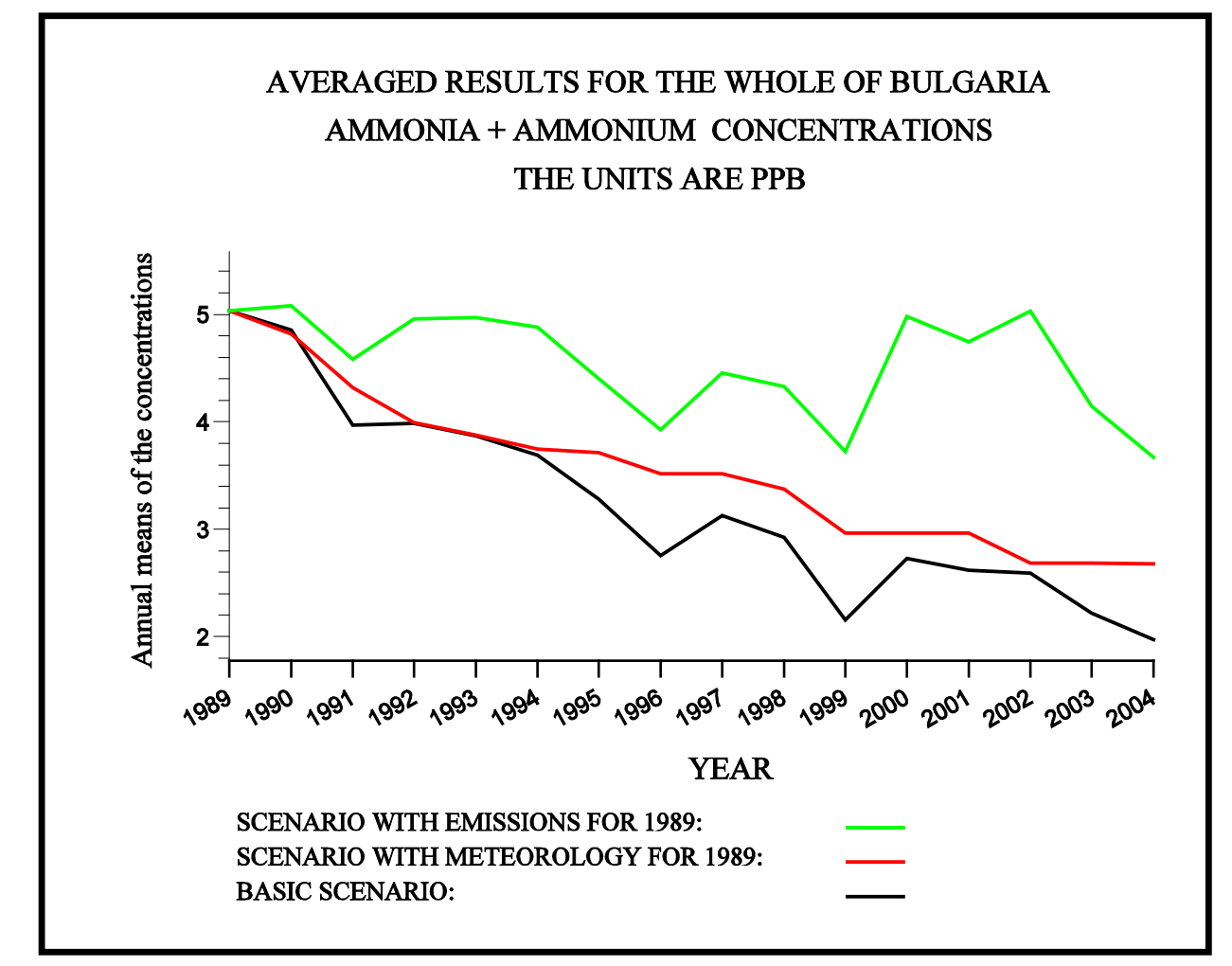

Figure 5. The Basic Scenario versus scenarios with constant emissions and meteorological conditions. 


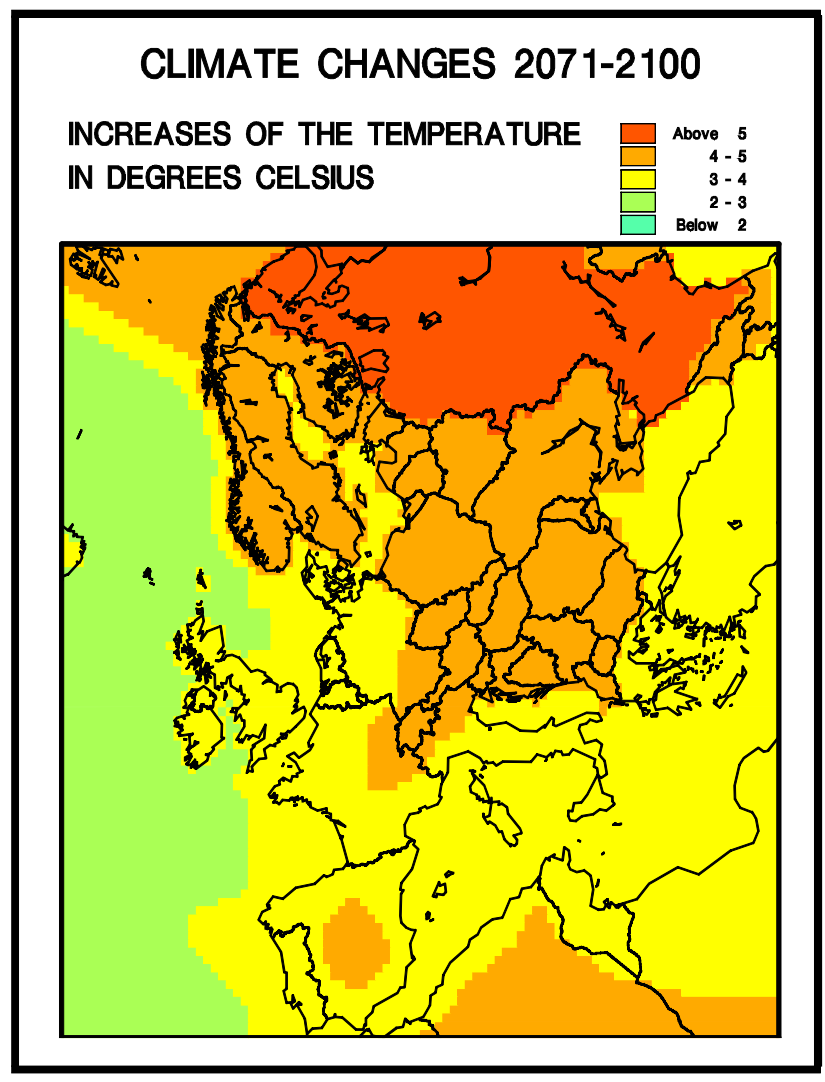

Figure 6. Temperature changes in Europe according to the IPCC Scenario SRES A2 from [23].

(b) there will be higher minimum temperatures, fewer cold days and fewer frost days over nearly all land areas and

(c) the diurnal temperature range will be reduced over land areas.

We increased the temperatures during the nighttime with a factor larger than the factor by which the daytime temperatures were increased. In this way the second and the third requirements are satisfied. The first requirement is satisfied as follows: during the summer periods, the daytime temperatures are increased by a larger amount in hot days. All these changes are carried out only over land. Furthermore, the temperatures were varied in such a way that the annual means of the changes remained the same, at all cells, as those in the first climatic scenario (i.e. as those prescribed in the IPCCS RES A2 Scenario). We also reduced (by 10\%) the cloud covers over land during the summer periods.

Climate Scenario 3: It is also expected, as shown in Table 9.6 on p. 575 in [23], that there will be more intense precipitation events but increased summer drying and associated risk of drought. We increased the precipitation events during winter (both over land and over water). During summer, the precipitation events in the continental parts of Europe were reduced. Similar changes in the humidity data were made. The cloud covers during winter were increased (by 10\%), while the same cloud covers as in the second climatic scenario were applied in the third climatic scenario during summer. Again, as in the previous two climatic scenarios, the mathematical expectation of the annual means of the changes of the temperature is the same as the predictions made in the IPCC SRES A2 Scenario.

A remark about the great computational complexity of problem handled when climatic scenarios are used should be given here. The task of running 14 scenarios over a time-period of 16 years on a fine grid $(480 \times 480$ $\times 10$ cells) is extremely demanding even when powerful modern computers are available. As mentioned above, the task of running so many scenarios over so long time-period can be successfully solved only if at least four requirements are simultaneously satisfied. These requirements are (a) fast but also sufficiently accurate numerical methods are to be implemented in the model, (b) the cache memories of the available computers have to be efficiently utilized, (c) codes which can be run in parallel have to be developed and used and (d) reliable and 
robust splitting procedures have to be implemented. The solution of sub-tasks (a)-(d) is discussed in detail in [8] and [13]. It must be emphasized here that it is impossible to handle the 14 scenarios over a time-period of 16 years on the available super-computers if the sub-tasks (a)-(d) are not efficiently solved. Even when this was done, it took more than two years to compute output data from all 2688 runs (14 scenarios $\times 16$ years $\times 12$ months) carried out in this study. This fact illustrates the great computational difficulties that are related to the investigation of various impacts of climatic changes on pollution levels. The storage requirements (the need for huge input and output files) are also enormous.

One can now ask an important question: Is it necessary to run the model on such a fine grid? An attempt to answer this question was carried out as follows. Two runs were performed. In the first run all European emissions sources were used, in the second one the emission sources in Bulgaria were set to zero. The ratios of the ozone concentrations of the second and the first runs are giving an evaluation of the contribution of the European sources to the ozone levels in Bulgaria. The results shown in Figure 7 show that this contribution is rather high (more than 65\%). This means that the commonly used approach based on introducing nested sub-domains will cause some difficulties with the determination of the boundary conditions (unless the boundaries are long away from Bulgaria, which means that the sub-domain including the Bulgaria area must be rather large). Therefore, we decided to use a fine grid discretization on the whole of Europe. This choice has the advantage that when we are interested in other parts of Europe (as in some of our previous studies) we do not need to run the model again with specifying other sub-domains.

Let us now, after justifying the need of fine grids, go back to the discussion of the climatic scenarios. The main purpose with the climatic scenarios developed and used in this paper can be described as follows. It is desirable to be able to compare directly the pollution levels obtained by using the predicted future temperatures

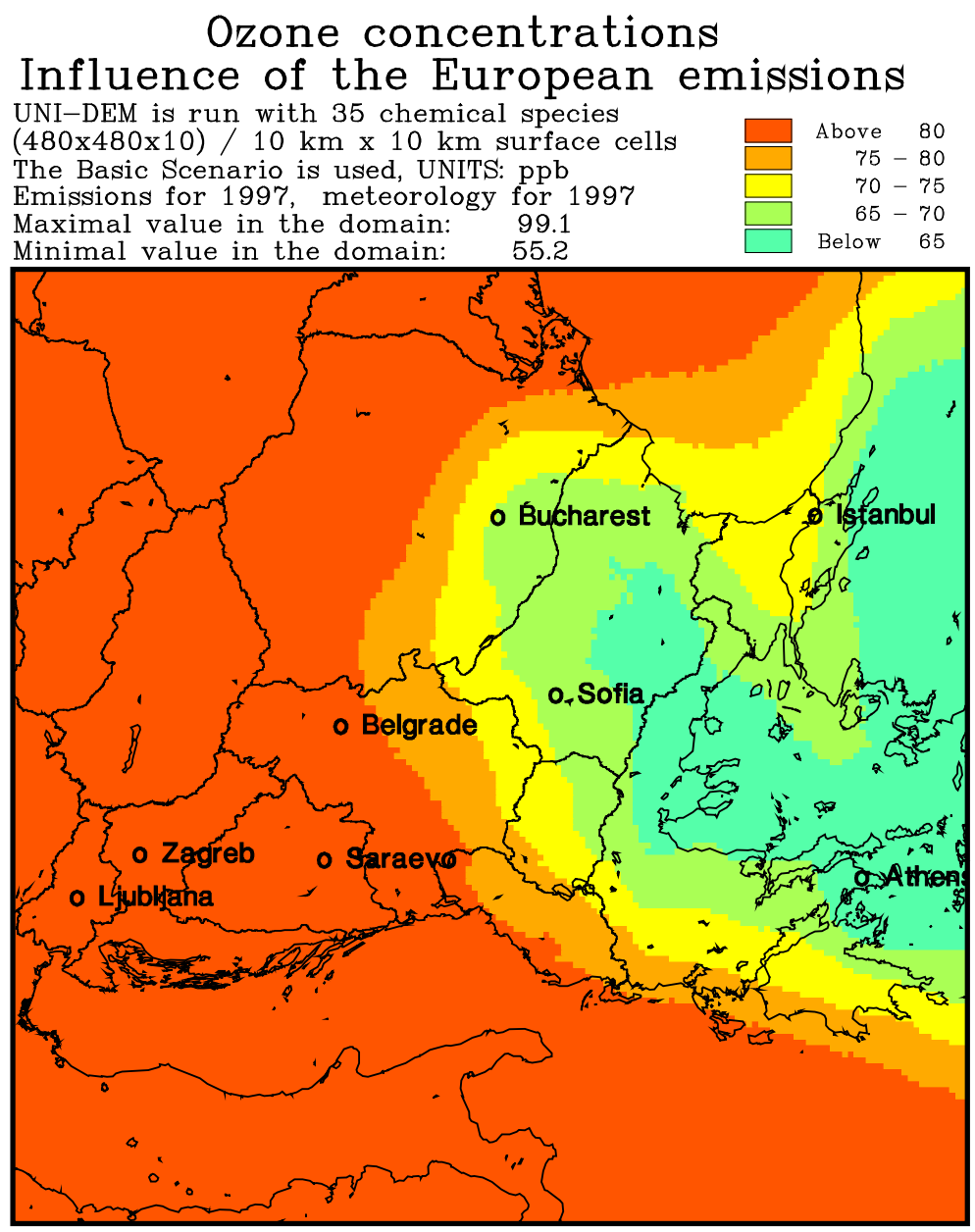

Figure 7. Influence of the ozone concentrations on transport from European countries. 
with the present state of the pollution levels. To achieve this we fixed the transport and varied only the temperatures and the emissions as well as some closely related to them quantities. For the sake of simplicity, assume that only the temperature is varied. Then the approach discussed in this paper has the advantage that it allows us to compare directly the present pollution levels with the pollution levels obtained with the increased temperature. Since the temperature is the only parameter that is varied, all changes of the ozone levels are clearly caused by the increased temperature levels. It is obvious that the same conclusion can be drawn if the emissions and some other parameters are also varied (the important issue being to keep the transport the same as that in the Basic Scenario).

Another approach can also be used; meteorological data obtained by a climatic model can be applied directly in our model. Such an action requires running a big climatic model. The problem is that it is not very clear in advance how to compare the results so found with the results obtained with the Basic Scenario, because the changes will be caused both by the increased temperature and by the different transport of the pollutants. On the other side, it will be possible to draw useful conclusions by performing runs over sufficiently long time-periods. The major problem is that the computational difficulties would be enormous when the fine discretization (10 km $\times 10 \mathrm{~km}$ surface cells) used in this paper is to be preserved.

The computational problems and the problems related to the storage needed to be kept and updated in the available computers will become even more challenging if the air pollution model is to be fully coupled with a climatic model. The advantage of such an approach will be the possibility to investigate also the feedback from the increased pollution levels to the climatic changes. At present it is not possible to resolve this problem on the whole European domain when fine spatial resolution is to be used. However, the computers are becoming more and more powerful and it will hopefully be possible to resolve the last two problems in the near future.

Some more details about the use of other approaches in the study of the impact of future climatic changes on air pollution levels can be found in [26] and [36] as well as in some of the references given in these two papers.

\section{Influence of the Climatic Changes on Bulgarian Pollution Levels}

The Basic Scenario was extensively compared with the three climatic scenarios that were discussed in previous section. Some results from this comparison have been presented in Figure 1. Much more results for other parts of Europe can be found in [1]-[6]. All results indicate that

(a) the daily maxima of the ozone concentrations obtained when the climatic scenarios are used are often (but not always) greater than those obtained by the Basic Scenarios and

(b) the differences (between the daily maxima of the ozone concentrations obtained with the climatic scenarios and those obtained with the Basic Scenario) are rather small.

It will be shown in this section that the second statement, (b), is not necessarily true when the "bad days" (to be defined below), which might cause damages on human beings are considered instead of averaged concentrations. In the latter case the differences can be considerably larger. The main conclusion is that it is much more relevant to consider not the annual means of the concentrations but directly the numbers of "bad days", which can be dangerous for our environment when exceed certain limits. Furthermore, it is important to establish whether the critical levels for these quantities, the "bad days", which are established by the EU Directive [14], are really exceeded or not. Assume that $c_{\max }$ is the maximum of the eight-hour averages of the calculated by some model or measured at some station ozone concentrations in a given day at some site $A$. If the condition $c_{\max }>60 \mathrm{ppb}$ is satisfied at least once during the day under consideration, then the expression a "bad day" will be used for such a day at site $A$. "Bad days" can have damaging effects on some groups of human beings (people who suffer from asthmatic diseases). Therefore, the number of such days should be reduced as much as possible. Two important aims are stated in the Ozone Directive issued by the EU Parliament issued in 2002 [14]. Target aim: The number of "bad days" in any site of the European Union should not exceed 25 after year 2010 and Long-term aim: No "bad day" should occur in the European Union.

The model results (including here model results reported in previous papers) indicate that these critical levels are greatly overestimated.

The numbers of "bad days" obtained in Dobrich (a town in the North-eastern part of Bulgaria, which is not very polluted where the first author was born) are given in Figure 8. It is seen that the numbers of bad days for the Climatic Scenario 4 are always greater than the corresponding numbers for the Basic Scenario. Moreover, the critical level of no more than 25 bad days is exceeded for many years of the studied period of 16 years. 
One may ask the question whether the increase shown in Figure 8 is big or small. The differences of the bad days obtained by the two scenarios were calculated and plotted in Figure 9. It is seen that for the town Dobrich these differences vary in the interval from three to seven. It is quite clear that such differences are considerable, because they show that sometimes the critical level may be exceeded in the Climatic Scenario 3, while the results for the Basic are acceptable. Results presented in [3] indicate that in some other parts of Europe the differences between the results obtained by the two scenarios are much bigger.

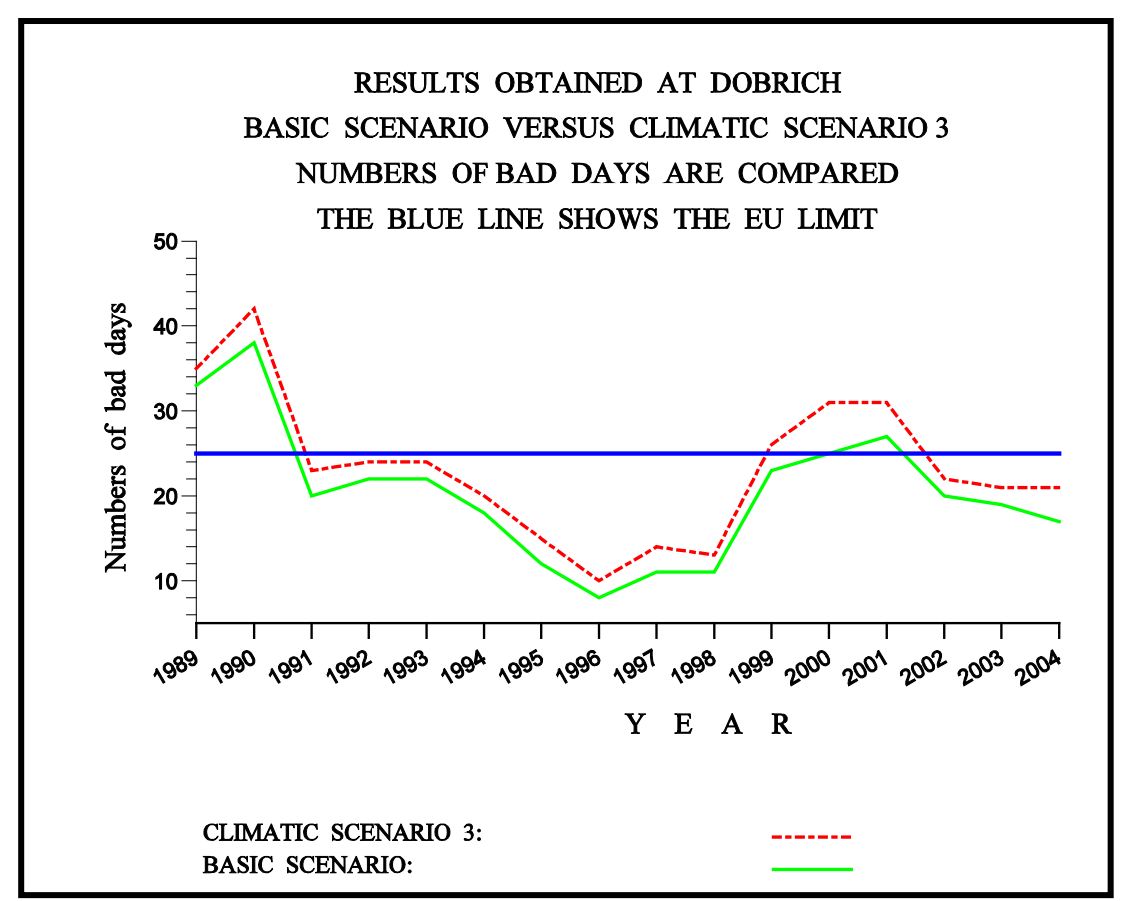

Figure 8. Comparing numbers of "bad days” obtained by using the Basic Scenario and Climatic Scenario 3.

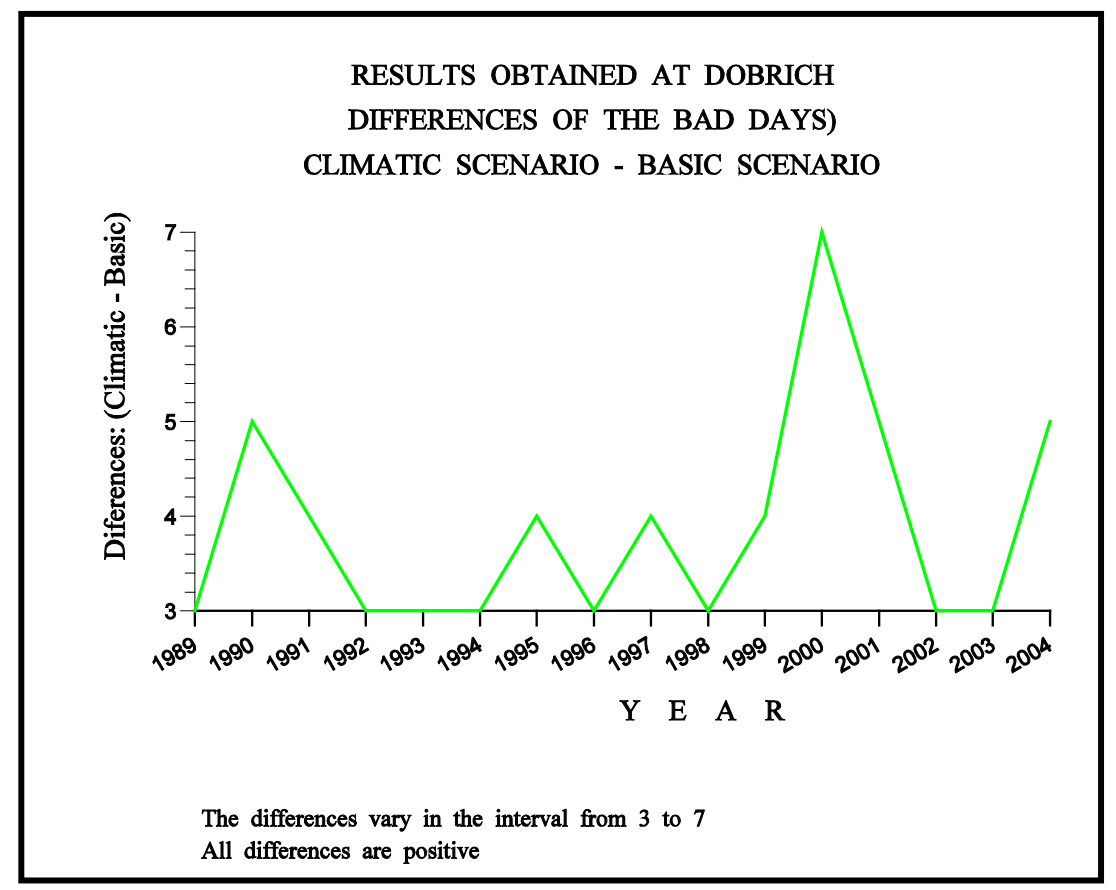

Figure 9. Comparing differences of "bad days" obtained by using the Basic Scenario and Climatic Scenario 3. 
The distribution of the numbers of bad days in Bulgaria for the last year in the studied period, year 2004, is shown in Figure 10. It is seen that the critical level prescribed in the directive issued by the European Union is exceeded in all regions of Bulgaria, excluding a relatively small area in the North-eastern part (where the town Dobrich is located). It should also be noted that the numbers of "bad days" in the Western part of the country are in general larger than those in the Eastern part. This is caused by the transportation of ozone pollutants from European sources and, thus, should be expected.

The increases of the numbers of "bad days" in 2004 when the Climatic Scenario 3 is used instead of the Basic Scenario are shown in Figure 11. It is clearly seen that in a very large part of the country the increases are greater than $15 \%$, which is a rather considerable amount.

Some scenarios with increased biogenic emissions (including increases not only of the biogenic emissions from forest trees, but also assuming the existence of biogenic emissions from crops) were developed and tested. The changes were made by following some recommendations made in [25] [27] and [28]. One of these scenarios, the Climatic Scenario 3 combined with Increased Biogenic Emissions was compared with the Basic Scenario. Results obtained in runs for 2004 are presented in Figure 12. It is seen that now the percentages of "bad days" found in the comparison of the results from this scenario with those calculated the Basic scenarios are greater than $15 \%$ in nearly whole territory of Bulgaria. This indicates that if the claims that the biogenic emissions are underestimated are correct, then the climatic changes will cause greater increases of some pollution levels.

It must be emphasized here that the results shown in Figures 10-12 are for year 2004. The code was run (as stated in the previous sections) for all sixteen years in the period from 1989 to 2004 and the trend remains the same for every year. In fact, for many years the increases are even bigger than those shown in these three figures.

\section{Numbers of bad days when \\ the Basic Scenario is used}

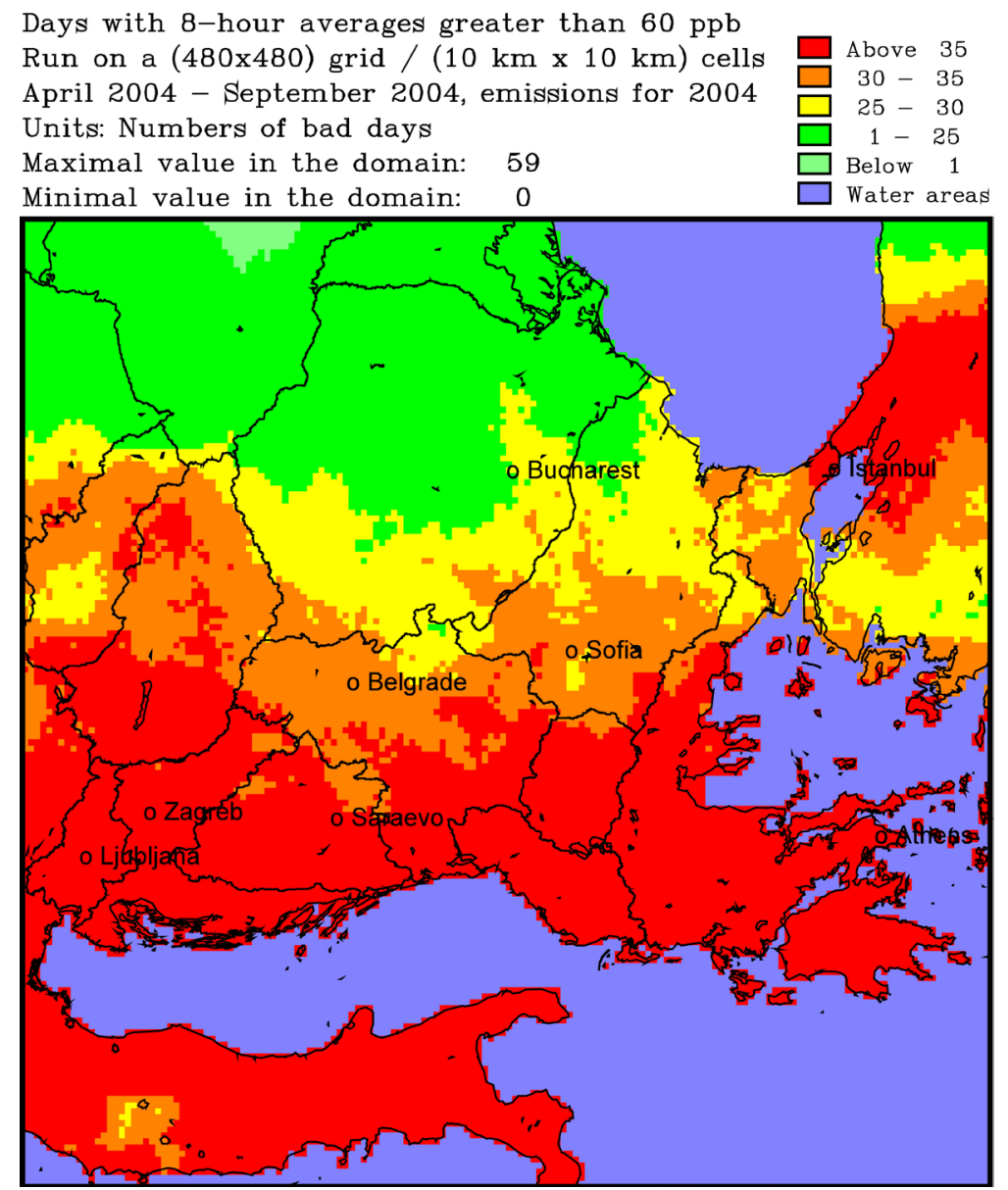

Figure 10. Distribution of the numbers of "bad days" in the different regions of Bulgaria. 


\section{Changes of the numbers of bad days 100 (Climate 3) / (Basic)}
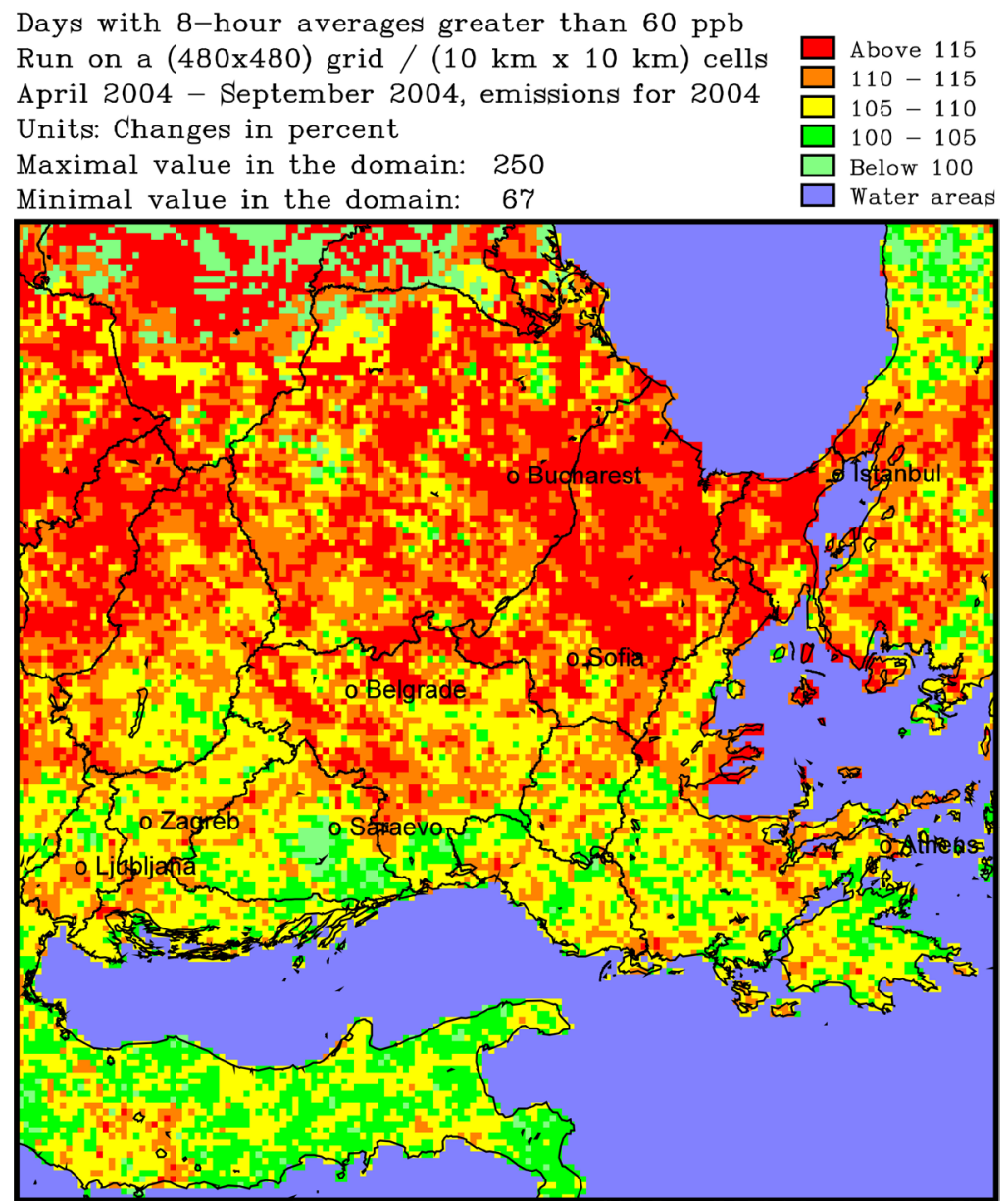

Figure 11. Climatic Scenario 3 versus the Basic Scenario: increases (in percent) of the numbers of bad days.

\section{Conclusions}

The results presented in this paper indicate very clearly that the climatic changes will increase the pollution levels related to ozone in Bulgaria. Similar results were reported in [1]-[6] for other countries in different parts of Europe. Moreover, the results that are reported in these papers show that the ozone levels in some European countries will be increased more than those in Bulgaria. However, the general trend does not change too much. Indeed, results obtained for areas from Russia and Ukraine to England and Spain and from Sweden and Denmark to Italy and Greece show clearly that independently of the fact that the pollution levels vary a lot for the different countries, the general tendency remains the same: the increase of the temperature will cause increases of many pollution levels. Therefore, the policy-makers must take into account the global warming effect during the preparation of strategies for keeping the future pollution levels under the prescribed critical levels. It is interesting to find the answer of the following question: By how much the amount of the anthropogenic emissions should be reduced in order to keep the pollution levels under the prescribed in [31] critical levels?

It should also be noted that a systematic application of algorithms based on advanced sensitivity analysis will improve both the presentation of the results and the understanding of the trends related to the increase of the pollution levels.

It must be emphasized here that better definitions related to critical levels of potentially dangerous pollutants are needed. Indeed, many of the critical levels, including here most of the critical levels that are required in the EU Ozone Directive [31], are not very carefully defined. For example, the determination of the quantity used in this paper, the "bad days", might be an extremely unstable process because in some situations it might be enormously 


\section{Changes of the numbers of bad days}

(Incr. biog. emis.)/(Basic Scenario)
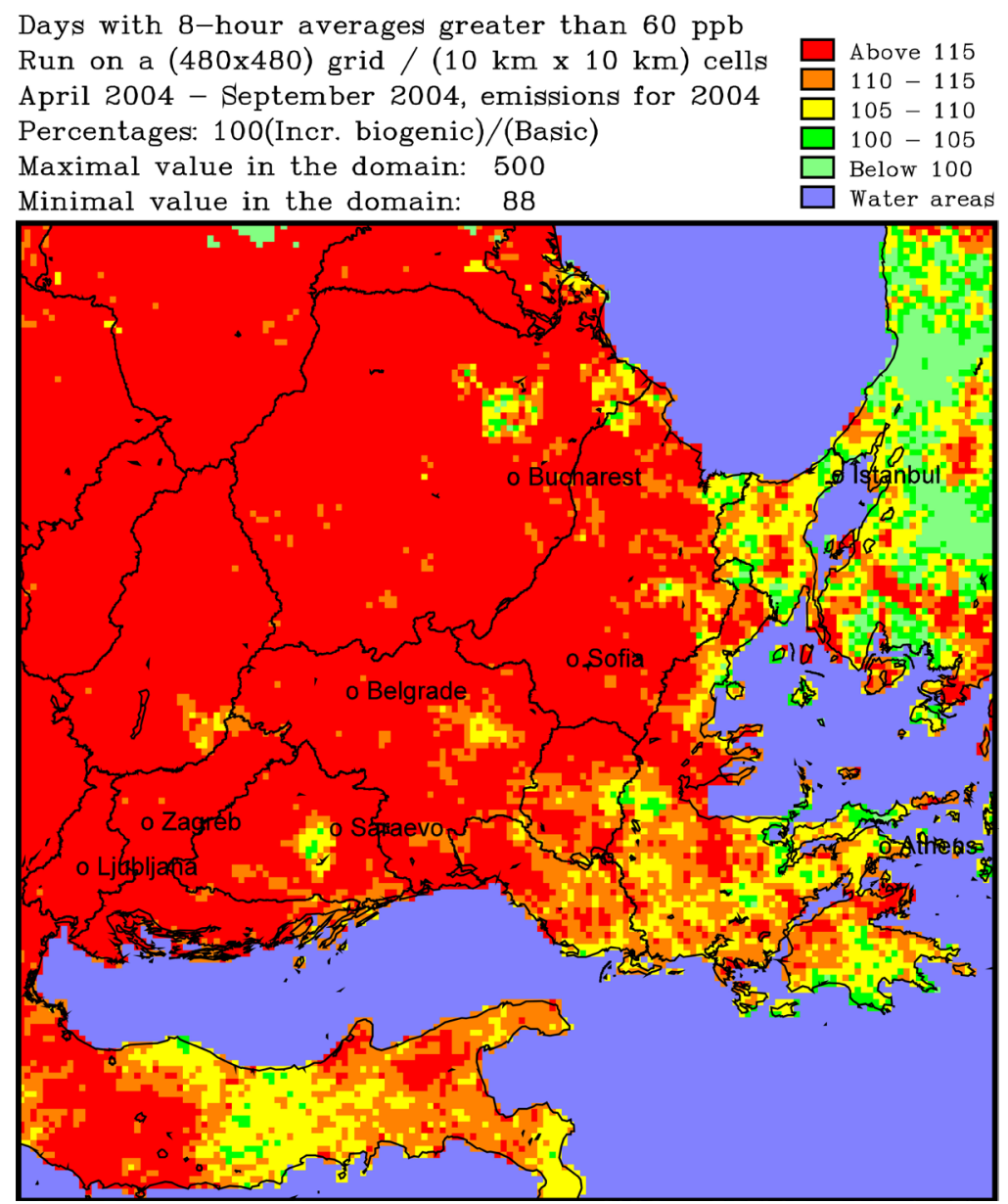

Figure 12. Additional increases when the biogenic emissions are increased.

sensitive to very small (even negligible) errors of model results or measurements. This fact creates difficulties in the preparation of reliable and robust control strategies. Therefore, it is necessary to try to stabilize the definitions. In connection with the "bad days", the use of the sharp limit of $60 \mathrm{ppb}$ is not a very good decision (in an extreme situation, the transition of the eight-hour average of the ozone concentration from $59.99 \mathrm{ppb}$ to 60.01 ppb will cause a shift from a "good day" to a "bad day"). It would be much more appropriate to introduce an uncertainty zone (let us call it, as in [3], a "grey zone"). For example, if the maximal eight-hour averaged ozone concentration is in the range of 40 to $80 \mathrm{ppb}$ then the day under consideration should be considered as belonging to the "grey zone". If this number is under $40 \mathrm{ppb}$ it will be appropriate to declare the day as a "good day", while it will certainly be "bad" if this number is bigger than $80 \mathrm{ppb}$. By applying this procedure, the uncertain cases will be accumulated in the "grey zone". The question is what to do with the "grey days". The simplest (but perhaps not the best) strategy will be to declare that $n$ "grey days" are equivalent to one "bad day". It will be necessary to perform a long series of systematic experiments in order to decide what value of $n$ should be chosen. More elaborated strategies can also be tried. For example, it is possible to use some weight coefficients (smaller weight coefficients should be used when the maximal eight-hour averaged ozone concentration is closer to the lower limit of $40 \mathrm{ppb}$ and larger weight coefficients in the opposite case). Finally, it is also possible to apply two upper limits: one for the "bad days" (say, 0 days) and one for the "grey days" (say 50 days).

\section{Acknowledgements}

K. Georgiev was partly supported by Grant DFNI I01/5 of the Bulgarian National Science Fund. 


\section{References}

[1] Csomós, P., Cuciureanu, R., Dimitriu, G., Dimov, I., Doroshenko, A., Faragó, I., Georgiev, K., Havasi, Á., Horváth, R., Margenov, S., Ostromsky, T., Prusov, V., Syrakov, D. and Zlatev, Z. (2006) Impact of Climate Changes on Pollution Levels in Europe. Final Report for a NATO Linkage Project (Grant 980505). http://www.cs.elte.hu/ faragois/NATO.pdf

[2] Dimov, I., Geernaert, G. and Zlatev, Z. (2008) Impact of Future Climate Changes on High Pollution Levels. International Journal of Environment and Pollution, 32, 200-230. http://dx.doi.org/10.1504/IJEP.2008.017103

[3] Zlatev, Z. (2010) Impact of Future Climate Changes on High Ozone Levels in European Suburban Areas. Climatic Change, 101, 447-483. http://dx.doi.org/10.1007/s10584-009-9699-7

[4] Zlatev, Z., Georgiev, K. and Dimov, I. (2013) Influence of Climatic Changes on Pollution Levels in the Balkan Peninsula. Computers and Mathematics with Applications, 65, 544-562. http://dx.doi.org/10.1016/j.camwa.2012.07.006

[5] Zlatev, Z., Havasi, Á. and Faragó, I. (2011) Influence of Climatic Changes on Pollution Levels in Hungary and Its Surrounding Countries. Atmosphere, 2, 201-221. http://dx.doi.org/10.3390/atmos2030201

[6] Zlatev, Z. and Moseholm, L. (2008) Impact of Climate Changes on Pollution Levels in Denmark. Environmental Modelling, 217, 305-319. http://dx.doi.org/10.1016/j.ecolmodel.2008.06.030

[7] Alexandrov, V., Owczarz, W., Thomsen, P.G. and Zlatev, Z. (2004) Parallel Runs of Large Air Pollution Models on a Grid of SUN Computers. Mathematics and Computers in Simulations, 65, 557-577. http://dx.doi.org/10.1016/j.matcom.2004.01.022

[8] AmbelasSkjøth, C., Bastrup-Birk, A., Brandt, J. and Zlatev, Z. (2000) Studying Variations of Pollution Levels in a Given Region of Europe during a Long Time-Period. Systems Analysis Modelling Simulation, 37, 297-311.

[9] Zlatev, Z. (1984) Application of Predictor-Corrector Schemes with Several Correctors in Solving Air Pollution Problems. BIT, 24, 700-715. http://dx.doi.org/10.1007/BF01934925

[10] Zlatev, Z. (1995) Computer Treatment of Large Air Pollution Models. Kluwer Academic Publishers, Dordrecht, Boston, London. http://dx.doi.org/10.1007/978-94-011-0311-4

[11] Zlatev, Z. (2001) Partitioning ODE Systems with an Application to Air Pollution Models. Computers and Mathematics with Applications, 42, 817-832. http://dx.doi.org/10.1016/S0898-1221(01)00201-2

[12] Zlatev, Z. (2002) Massive Data Sets Issues in Air Pollution Modelling. In: Abello, J., Pardalos, P.M. and Resende, M.G.C., Eds., Handbook on Massive Data Sets in Science and Engineering, Kluwer Academic Press, Dordrecht, Boston, London, 1169-1220. http://dx.doi.org/10.1007/978-1-4615-0005-6_31

[13] Zlatev, Z. and Dimov, I. (2006) Computational and Numerical Challenges in Environmental Modelling. Elsevier, Amsterdam.

[14] Zlatev, I. and Syrakov, D. (2004) A Fine Resolution Modelling Study of Pollution Levels in Bulgaria. Part 1: $\mathrm{SO}_{\mathrm{x}}$ and $\mathrm{NO}_{\mathrm{x}}$ Pollution. International Journal of Environment and Pollution, 22, 186-202. http://dx.doi.org/10.1504/IJEP.2004.005508

[15] Zlatev, Z. and Syrakov, D. (2004) A Fine Resolution Modelling Study of Pollution Levels in Bulgaria. Part 2: High Ozone Levels. International Journal of Environment and Pollution, 22, 203-222. http://dx.doi.org/10.1504/IJEP.2004.005513

[16] Bastrup-Birk, A., Brandt, J., Uria, I. and Zlatev, Z. (1997) Studying Cumulative Ozone Exposures in Europe during a 7-Year Period. Journal of Geophysical Research, 102, 23917-23035. http://dx.doi.org/10.1029/97JD01966

[17] Zlatev, Z., Dimov, I., Ostromsky, Tz., Geernaert, G., Tzvetanov, I. and Bastrup-Birk, A. (2001) Calculating Losses of Crops in Denmark Caused by High Ozone Levels. Environmental Modelling and Assessment, 6, 35-55. http://dx.doi.org/10.1023/A:1011554912198

[18] Abdalmogith, S., Harrison, R.M. and Zlatev, Z. (2006) Intercomparison of Inorganic Aerosol Concentrations in the UK with Predictions of the Danish Eulerian Model. Journal of Atmospheric Chemistry, 54, 43-66. http://dx.doi.org/10.1007/s10874-006-9012-3

[19] Havasi, Á., Bozó, L. and Zlatev, Z. (2001) Model Simulation on Transboundary Contribution to the Atmospheric Sulfur Concentration and Deposition in Hungary. Idöjárás, 105, 135-144.

[20] Havasi, Á. and Zlatev, Z. (2002) Trends of Hungarian Air Pollution Levels on a Long Time-Scale. Atmospheric Environment, 36, 4145-4156. http://dx.doi.org/10.1016/S1352-2310(02)00198-X

[21] Harrison, R.M., Zlatev, Z. and Ottley, C.J. (1994) A Comparison of the Predictions of an Eulerian Atmospheric Transport Chemistry Model with Experimental Measurements over the North Sea. Atmospheric Environment, 28, 497516. http://dx.doi.org/10.1016/1352-2310(94)90127-9

[22] Hass, H., van Loon, M., Kessler, C., Stern, R., Mathijsen, J., Sauter, F., Zlatev, Z., Langner, J., Foltescu, V. and Schaap, 
M. (2004) Aerosol Modelling: Results and Intercomparison from European Regional-Scale Modelling Systems. GSFNational Research Center for Environment and Health, International Scientific Secretariat, EUROTRAC, Münich.

[23] Roemer, M., Beekman, M., Bergsröm, R., Boersen, G., Feldmann, H., Flatøy, F., Honore, C., Langner, J., Jonson, J.E., Matthijsen, J., Memmesheimer, M., Simpson, D., Smeets, P., Solberg, S., Stevenson, D., Zandveld, P. and Zlatev, Z. (2004) Ozone Trends according to Ten Dispersion Models. GSF-National Research Center for Environment and Health, International Scientific Secretariat, EUROTRAC, Münich.

[24] Amann, M., Bertok, I., Cofala, J., Gyarfas, F., Heyes, C., Klimont, Z., Makowski, M., Schöpp, W. and Syri, S. (1999) Cost-Effective Control of Acidification and Ground-Level Ozone. Seventh Interim Report, International Institute for Applied System Analysis (IIASA), A-2361, Laxenburg.

[25] Anastasi, C., Hopkinson, L. and Simpson, V.J. (1991) Natural Hydrocarbon Emissions in the United Kingdom. Atmospheric Environment, 25, 1403-1408. http://dx.doi.org/10.1016/0960-1686(91)90249-7

[26] Bell, M.L., Goldberg, R., Hogrefe, C., Kinney, P.L., Knowlton, K., Lynn, B., Rosenthal, J., Rosenzweig, C. and Patz, A. (2007) Climate Change, Ambient Ozone, and Health in 50 US Cities. Climatic Change, 82, 61-76. http://dx.doi.org/10.1007/s10584-006-9166-7

[27] Bouchet, V.S., Laprise, R., Torlaschi, E. and McConnel, J.C. (1999) Studying Ozone Climatology with a Regional Climate Model: 1. Model Description and Evaluation. Journal of Geophysical Research, 104, 30351-30371. http://dx.doi.org/10.1029/1999JD900805

[28] Bouchet, V.S., Laprise, R., Torlaschi, E., McConnel, J.C. and Plummer, D.A. (1999) Studying Ozone Climatology with a Regional Climate Model: 2. Climatology. Journal of Geophysical Research, 104, 30373-30385. http://dx.doi.org/10.1029/1999JD900806

[29] Carvalho, A., Monteiro, A., Solman, S., Miranda, A.I. and Borrego, C. (2010) Climate-Driven Changes in Air Quality over Europe by the End of the 21st Century, with Special Reference to Portugal. Environmental Science and Policy, 13, 445-458. http://dx.doi.org/10.1016/j.envsci.2010.05.001

[30] Intergovernmental Panel on Climate Change (2007) Climate Change the Physical Science Basis Contribution of the Working Group I to the Fourth Assessment Report of IPCC (Intergovernmental Panel on Climate Change). Cambridge University Press, Cambridge.

[31] European Parliament (2002) Directive 2002/3/EC of the European Parliament and the Council of 12 February 2002 Relating to Ozone in Ambient Air. Official Journal of the European Communities, L67, 14-30.

[32] EMEP (1999) Emission Data, Status Report EMEP/MSC-W Report 1/99. Meteorological Synthesizing Centre—West, Norwegian Meteorological Institute, Oslo, Norway.

[33] EMEP Home (2006) http://www.emep.int/index data.html

[34] Geernaert, G. and Zlatev, Z. (2004) Studying the Influence of the Biogenic Emissions on the AOT40 Levels in Europe. International Journal of Environment and Pollution, 23, 29-41. http://dx.doi.org/10.1504/IJEP.2004.005485

[35] Houghton, J.T., Ding, Y., Griggs, D.J., Noguer, M., van der Linden, P.J., Dai, X., Maskell, K. and Johnson, C.A., Eds. (2001) Climate Change 2001: The Scientific Basis. Cambridge University Press, Cambridge.

[36] Jacobson, M.Z. (2008) On the Causal Link between Carbon Dioxide and Air Pollution Mortality. Geophysical Research Letters, 35, L03809. http://dx.doi.org/10.1029/2007gl031101

[37] Lübkert, B. and Schöpp, W. (1989) The OECD-Map Emission Inventory for, and in Western Europe. Report No. WP89-082, International Institute for Applied Systems and Analysis (IIASA), Laxenburg.

[38] Simpson, D., Guenther, A., Hewitt, C.N. and Steinbrecher, R. (1995) Biogenic Emissions in Europe: I. Estimates and Uncertainties. Journal of Geophysical Research, 100, 22875-22890. http://dx.doi.org/10.1029/95JD02368 


\section{Submit or recommend next manuscript to SCIRP and we will provide best service for you:}

Accepting pre-submission inquiries through Email, Facebook, LinkedIn, Twitter, etc.

A wide selection of journals (inclusive of 9 subjects, more than 200 journals)

Providing 24-hour high-quality service

User-friendly online submission system

Fair and swift peer-review system

Efficient typesetting and proofreading procedure

Display of the result of downloads and visits, as well as the number of cited articles

Maximum dissemination of your research work

Submit your manuscript at: http://papersubmission.scirp.org/ 